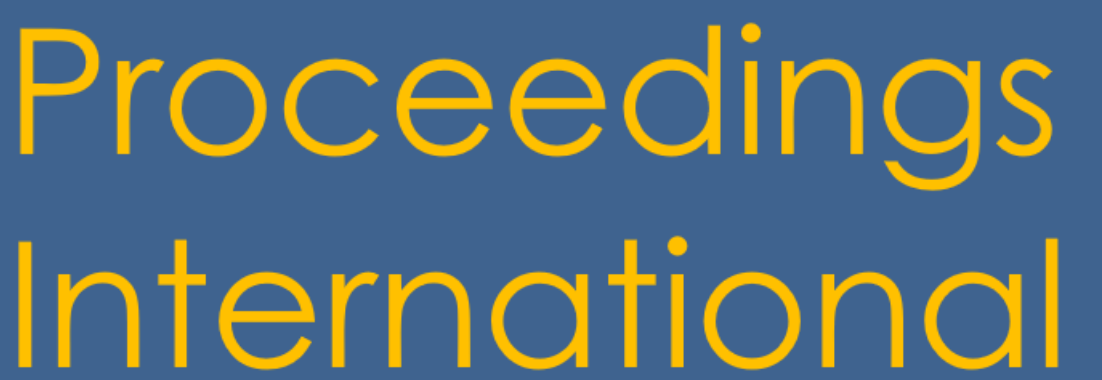

\title{
Nanostructured coatings based on silver nanoparticles with applications in anti- infectious therapy
}

B.S. Vasile 1,2, A.C. Bîrcă 1,2, A.M. Grumezescu 1,2, F. Iordache ${ }^{4}$, A.M. Holban ${ }^{3}$, A.O. Stoica ${ }^{1,2}$, I.A. Neacșu 1,2, V.A. Surdu 1,2, R. Trușcă ${ }^{1,2}$.

1 Faculty of Applied Chemistry and Materials Science, Politehnica University of Bucharest, Bucharest, 060042, Romania

2 National Centre for Micro and Nanomaterials, Politehnica University of Bucharest, Bucharest, 060042, Romania

3 Microbiology Immunology Department, Faculty of Biology, University of Bucharest, Bucharest, 050095, Romania

4 Faculty of Veterinary Medicine, University of Agronomic Science and Veterinary Medicine, Bucharest, 011464, Romania * Correspondence: ada_birca@yahoo.com; Scopus ID: 57203357672

The increasingly concerning cases regarding patients presenting wound infections caused by antibiotic treatment resistance for multiple bacterial strains led to advanced researches that help with resolution of this common problem that may ultimately result in death. Regarding healing of wounds caused by trauma, many parameters that influence after treatment results need to be taken into consideration, like choosing the cleansing technique in the first stage of the wound and optimizing the type of wound dressing used, preferable to present all the characteristics necessary for the type of wound and cicatrization of the wound to be hard to identify after healing [1,2].

For this purpose, the theme of this paper targets the use of wound dressings functionalized with silver nanoparticles and polymeric layer of alginate in anti-infectious therapy, which contributes successfully in resolving the problem about the possibility of infection at the wound site and sustain a faster healing. The paper presents the analysis methods applied on the samples, using SEM, TEM, XRD and biological tests of cellular viability and antimicrobial tests, which demonstrated effective results of the silver nanoparticles in anti-infectious therapy.

Keywords: coatings, silver nanoparticles, anti-infectious therapy.

\section{Funding}

Not applicable.

\section{Acknowledgments}

Not applicable.

\section{Conflicts of Interest}

The authors declare no conflict of interest.

Cite This Work: B.S. Vasile, A.C. Bîrcă, A.M. Grumezescu, F. Iordache, A.M. Holban, A.O. Stoica, I.A. Neacșu, V.A. Surdu, R. Trușcă Nanostructured coatings based on silver nanoparticles with applications in anti-infectious therapy. Proceedings Int 2019, 1, 0017-0018. 
B.S. Vasile, A.C. Bîrcă, A.M. Grumezescu, F. lordache, A.M. Holban, A.O. Stoica, I.A. Neacșu, V.A. Surdu, R. Trușcă
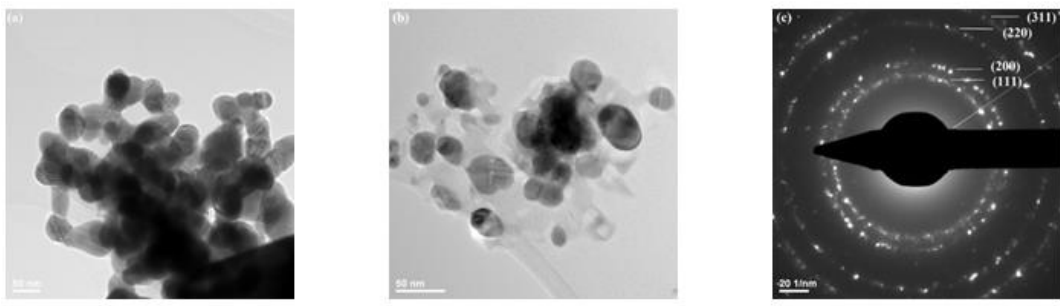

Figure 1. TEM images and SAED image for Silver Nanoparticles.
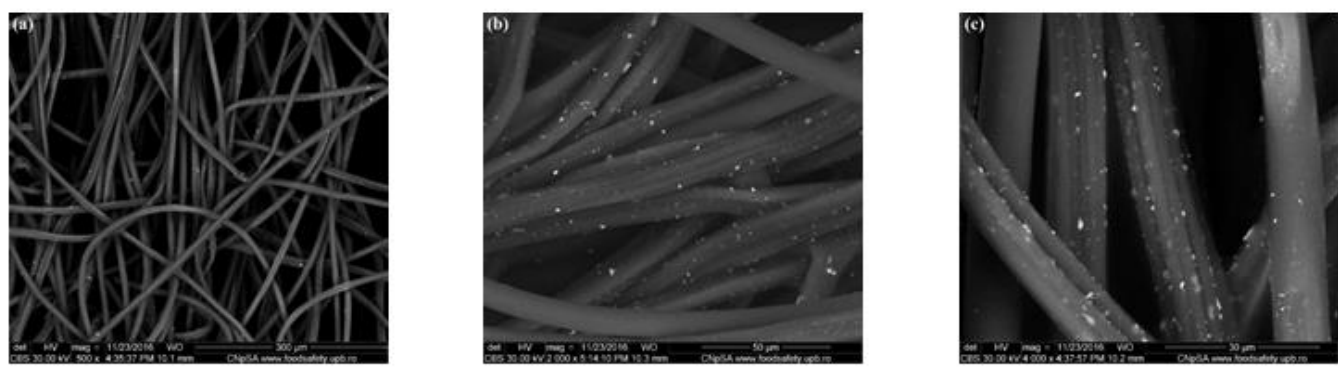

Figure 2. SEM images for covered dressing with silver nanoparticles and alginate layer.
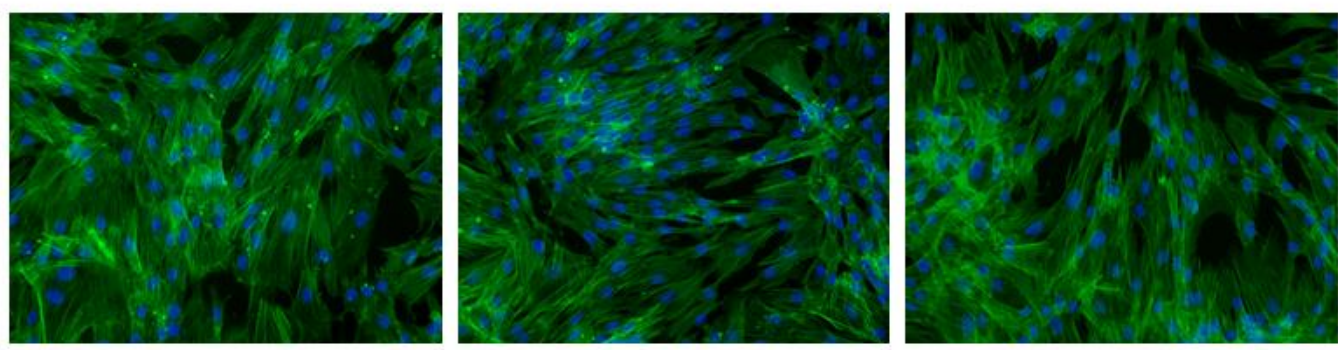

Figure 3. Fluorescent microscopy of fibroblast cells in contact with the obtained dressing.

\section{References}

1. Lee, K.Y.; Mooney, D.J. Alginate: Properties and biomedical applications. Progress in Polymer Science 2012, 37, 106-126, https://doi.org/10.1016/j.progpolymsci.2011.06.003. 2. Woo, K.Y.; Coutts, P.M.; Sibbald, R.G. A Randomized Controlled Trial to Evaluate an
Antimicrobial Dressing with Silver Alginate Powder for the Management of Chronic Wounds Exhibiting Signs of Critical Colonization. Advances in Skin \& Wound Care 2012, 25, 503-508, https://doi.org/10.1097/01.ASW.0000422628.63148.4b 